\title{
Vergelijkende erfelijke en pathogenische kenmerken van hypertrofische cardiomyopathie bij de kat en de mens
}

\author{
Comparative hereditary and pathogenic characteristics of hypertrophic \\ cardiomyopathy in cats and humans
}

\author{
M. Lhomme, R. Ducatelle \\ Vakgroep Pathologie, Bacteriologie en Pluimveeziekten \\ Faculteit Diergeneeskunde, Universiteit Gent, \\ Salisburylaan 133, B-9820 Merelbeke \\ Michelle.Lhomme@Ugent.be
}

\section{AMENVATTING}

Hypertrofische cardiomyopathie (HCM) wordt gekenmerkt door een hypertrofisch, nietgedilateerd linkerventrikel. Met een prevalentie van ongeveer $0,2 \%$ bij mensen en $15 \%$ bij katten is dit één van de meest voorkomende hartafwijkingen. In het merendeel van de gevallen is de aandoening erfelijk bepaald, maar ze kan ook verworven zijn. De klinische symptomen zijn variabel. Genotypisch aangetaste individuen kunnen (ernstige) symptomen van hartfalen vertonen of zelfs abrupt sterven, maar ze kunnen ook gedurende heel het leven asymptomatisch blijven.

Er zijn bij de mens reeds meer dan 1400 polymorfismen gedetecteerd in dertien genen die coderen voor sarcomeereiwitten in het hart. Een deel van deze hebben een invloed op het aangemaakte eiwit en zijn, samen met modificerende genen en omgevingsfactoren, verantwoordelijk voor de ontwikkeling van hypertrofische cardiomyopathie. Bij de kat werden tot op heden slechts drie mutaties geïdentificeerd in een gen dat codeert voor één sarcomeereiwit. Voor deze drie mutaties bestaan reeds commerciële diagnostische testen. Deze mutaties zijn slechts verantwoordelijk voor een kleine fractie van de gevallen van HCM bij de kat. Wil men preventief ingrijpen, dan is het van belang om zo veel mogelijk oorzakelijke mutaties te kennen.

Er zijn veel raakpunten tussen de feliene en humane vorm van hypertrofische cardiomyopathie. Zowel de manier van overerven (autosomaal) als de klinische verschijning en de histopathologische veranderingen komen overeen tussen de verschillende species. Er is echter nog te weinig bekend over de sarcomeereiwitten en hun mutaties om informatie te extrapoleren van mens naar kat en vice versa.

\section{ABSTRACT}

Hypertrophic cardiomyopathy (HCM) is characterized by a hypertrophic, non-dilated left ventricle. With a prevalence of approximately $0.2 \%$ in humans and $15 \%$ in cats, this is one of the most common heart diseases. The disorder is often inherited but may also be acquired during life. The clinical symptoms may differ. Genotypically affected individuals can exhibit (severe) symptoms of heart failure or die suddenly, but they can also stay asymptomatic during their entire life.

More than 1400 gene polymorphisms have already been detected in thirteen genes that code for sarcomere proteins in the heart in humans. Some of them are, together with modifying genes and environmental factors, responsible for the development of HCM. To date, only three mutations have been identified in cats. Commercial tests are already available to diagnose them. These mutations are responsible for only a small fraction of the cases of HCM in cats. It is important to identify as many mutations as possible in order to develop a control strategy.

There are a lot of common grounds between the human and feline forms of HCM. There are similarities in the mode of inheritance (autosomal), the clinical appearance and the histopathological changes. Still, there is not enough known about sarcomere proteins and their mutations to extrapolate information from humans to cats and vice versa. 


\section{INLEIDING EN DEFINITIE}

Cardiomyopathie is een term die gebruikt wordt voor een groep van aandoeningen waarbij de contractiekracht van de hartspier (geleidelijk) vermindert. Er wordt een onderscheid gemaakt tussen hypertrofische en dilatorische cardiomyopathie. De eerste aandoening wordt gekenmerkt door hypertrofie van de hartspier, de tweede door dilatatie. Hypertrofische cardiomyopathie kan primair of secundair zijn. De hartspierschade bij secundaire cardiomyopathie is een gevolg van systemische of multiorgaanaandoeningen (endocrien, toxisch, inflammatoir, etc.) (Elliott et al., 2008). Primaire hypertrofische cardiomyopathie is een van de meest voorkomende erfelijke hartafwijkingen bij zowel mens als kat. Bij deze aandoening komt een hypertrofisch, niet-gedilateerd linkerventrikel voor die niet secundair is aan andere hart- of systemische aandoening. Deze pathologie wordt veroorzaakt door mutaties in genen die coderen voor eiwitten in sarcomeren van de hartspier (Haggstrom 2003; Maron en Maron 2012; Tao et al., 2013).

Feliene hypertrofische cardiomyopathie heeft veel rakpunten met de humane vorm, zowel in de manier van overerven (autosomaal), als in de klinische manifestatie en de histopathologische veranderingen. Hierop was de hoop gevestigd dat bevindingen bij de mens geëxtrapoleerd zouden kunnen worden naar de kat en vice versa. Toch is er tot op heden nog geen verband gelegd tussen de oorzakelijke genmutaties bij de mens en de kat (Kittleson et al., 1999; Haggstrom, 2003). Kennis en detectie van dergelijke oorzakelijke mutaties zijn belangrijk voor de diagnose, therapie en prognose van de aandoening.

\section{PATHOLOGIE EN PREVALENTIE}

Zowel bij de mens als bij de kat wordt hypertrofische cardiomyopathie gekenmerkt door een verdikte linkerventrikelwand met een normaal tot verkleind ventrikel tot gevolg. De papillairspieren en het interventriculair septum zijn ook verdikt (Klues et al., 1991; Kienle, 2008). Voorgenoemde veranderingen komen in verschillende gradaties voor: mild, matig of erg. Bij primaire HCM zijn er geen tekens van onderliggende oorzaken, zoals valvulaire, coronaire of congenitale afwijkingen of hypertensie (Brouwer et al., 2010). De klinische evolutie varieert van individu tot individu. Sommige genotypisch aangetaste individuen blijven gedurende heel hun leven asymptomatisch. Anderen vertonen ernstige symptomen van hartfalen of angina pectoris. Dit laatste is vooral typisch bij de mens en niet bij de kat). Nog anderen ontwikkelen trombo-embolieën of sterven plots (Brouwer et al., 2010).

Het fenotype is enerzijds afhankelijk van de oorzakelijke mutatie en anderzijds van de invloed van modificerende genen en omgevingsfactoren. Er is dus een hoge variabiliteit in expressie bij hypertro- fische cardiomyopathie, aangezien niet alle patiënten dezelfde symptomen vertonen. Toch is de aanwezige genmutatie voor een groot deel bepalend voor de leeftijd waarop de aandoening zich ontwikkelt en de ergheid van de symptomen (Richard et al., 2006). Door de genetische heterogeniteit en de variabele klinische expressie van deze aandoening blijft de relatie tussen genotype en fenotype complex, zelfs bij de mens (Xu et al., 2010).

Hypertrofische cardiomyopathie heeft een prevalentie van ongeveer $0,2 \%$ bij de mens (Maron et al., 1995) en maar liefst 15\% bij de kat (Paige et al., 2009). Het merendeel van de aangetaste katten is een raskat, met de hoogste prevalentie bij de maine coon, ragdoll en Britse korthaar, maar de aandoening kan in principe bij alle rassen en kruisingen voorkomen (Kittleson et al., 1999; Meurs et al., 2009).

MUTATIES IN HET GENOOM EN HET VERBAND MET CARDIOMYOPATHIE BIJ DE MENS

De afgelopen twintig jaar zijn er meer dan 1400 polymorfismen geïdentificeerd in dertien genen die een rol spelen in de ontwikkeling van cardiomyopathie. Het merendeel van deze polymorfismen bevindt zich in genen die coderen voor myofilamenten van sarcomeren, Z-band-eiwitten en $\mathrm{Ca}^{2+}$ dragende proteïnen (Maron et al., 2012). HCM is een autosomaal dominante aandoening met onvolledige penetrantie en variabele expressie. Studies hebben aangetoond dat 20 tot $30 \%$ van de volwassen dragers gezond is ( $\mathrm{Ri}-$ chard et al., 2006). Individuen die homozygoot zijn voor een mutatie of heterozygoot zijn voor twee of meerdere mutaties, vertonen meestal ernstigere symptomen (Mary et al., 2010; Xu et al., 2010). Sporadisch vinden er de novo-mutaties plaats, waardoor een aangetast individu met twee niet-aangetaste ouders ontstaat (Maron en Maron, 2012). De meeste van deze mutaties zijn privaat, dit wil zeggen dat ze meestal in slechts één familie voorkomen.

\section{Sarcomeereiwit mutaties}

In Tabel 1 worden de sarcomeerproteïnen met de grootste invloed op de ontwikkeling van hypertrofische cardiomyopathie bij de mens opgesomd. Veel van deze proteïnen zijn belangrijk in de cytoarchitectuur en de mechanosensorische signalisatie van de hartspiercel (Xu et al., 2010). Over het algemeen vertonen patiënten met mutaties in de sarcomeren een ergere hypertrofie en worden ze op jongere leeftijd aangetast dan patiënten zonder een bekende ziekteveroorzakende mutatie (Van Driest et al., 2005) (Tabel 1).

Cardiogene myosine-bindingsproteïne C (MYBPC3) is een eiwit dat een zeer belangrijke rol speelt in de regulatie van de sarcomeerfunctie. Het wordt gecodeerd door het $M Y B P C 3$-gen. Enkel dit sarcomeereiwit en 
Tabel 1. De meest voorkomende sarcomeermutaties bij de mens (naar Xu et al., 2010).

\begin{tabular}{|c|c|c|c|c|c|}
\hline Sarcomeereiwit/gen & $\begin{array}{l}\text { Frequentie } \\
\text { mutatie bij } \\
\text { HCM- } \\
\text { patiënten (\%) }\end{array}$ & $\begin{array}{l}\text { Aantal } \\
\text { mutaties } \\
\text { aangetroffen } \\
\text { in gen }\end{array}$ & $\begin{array}{l}\text { Vroegste } \\
\text { (gepubliceerde) } \\
\text { leeftijd plotse } \\
\text { sterfte door } \\
\text { HCM (jaar) }\end{array}$ & $\begin{array}{l}\text { Aantal } \\
\text { goedaardige/ } \\
\text { milde } \\
\text { gevallen (\%) }\end{array}$ & $\begin{array}{l}\text { Gemiddelde } \\
\text { leeftijd } \\
\text { 1ste klinische } \\
\text { symptomen } \\
\text { (jaar) }\end{array}$ \\
\hline $\begin{array}{l}\text { B-myosine zware keten / } \\
\text { MYH7 }\end{array}$ & $25-35$ & 233 & 2 & 0,07 & 25,6 \\
\hline $\begin{array}{l}\text { Cardiogene myosine binding } \\
\text { proteïne C / MYBPC3 }\end{array}$ & $20-30$ & 187 & 13 & 19,79 & 33 \\
\hline Cardiogene troponine $\mathrm{T}$ / TNNT2 & $3-5$ & 39 & 12 & 0,08 & 30 \\
\hline Cardiogene troponine I / TNNI3 & $<5$ & 37 & 14 & 0,05 & 33 \\
\hline Tropomyosine $1 \alpha$ / TPM1 & $<5$ & 15 & 27 & 0 & 23,2 \\
\hline $\begin{array}{l}\text { Cardiogene regulerend myosine } \\
\text { lichte keten } 2 \text { / MYL2 }\end{array}$ & $<5$ & 13 & Onvoldoende data & 0,38 & Onvoldoende data \\
\hline $\begin{array}{l}\text { Essentiële myosine lichte } \\
\text { keten 3/MYL3 }\end{array}$ & Zeldzaam & 7 & 28 & 0,14 & 17,3 \\
\hline$\alpha$-Cardiogene actine / ACTC & Zeldzaam & 7 & 1 & 0,71 & 20,7 \\
\hline Cardiogene troponine $\mathrm{C} / \mathrm{TNNC1}$ & Zeldzaam & 7 & 21 & 0 & 27,1 \\
\hline
\end{tabular}

zijn mutaties worden hier nader besproken, aangezien dit het enige eiwit is waarin tot op heden met HCMgerelateerde mutaties werden aangetroffen bij de kat. MYBPC3 heeft twee belangrijke functies:

1. MYBPC3 is van belang in de regulatie van de contractie van de hartspier via fosforylatie. Fosforylatie gebeurt voornamelijk door proteïnekinase A die wordt gestimuleerd door $\beta$-adrenerge agonisten, zoals adrenaline. De fosforylatie van MYBPC3 verhoogt de gevoeligheid van de myofilamenten voor calcium, verlaagt de passieve stijfheid van de hartspier en verhoogt de krachtontwikkeling tijdens systole en de relaxatiesnelheid tijdens diastole (Winegrad, 1999; Kuster et al., 2012).

2. Bovendien heeft MYBPC3 een rol in het behoud van de structuur van myosine via binding aan titine. Zowel myosine als titine moet vastgehecht worden aan MYBPC3 om een stevige, stabiele binding te waarborgen (Flashman et al., 2004).

Mutaties in het MYBPC3-gen kunnen leiden tot het verlies of een verandering van verschillende zones in de proteïne, zoals de zone waar binding plaatsvindt aan myosine of titine of de zone waar fosforylatie gebeurt. Op deze manier wordt de hartfunctie beïnvloed en kan HCM zich ontwikkelen (Winegrad, 1999; Flashman et al., 2004).

Studies wijzen erop dat haplo-insufficiëntie soms de oorzaak is van pathologische veranderingen in de hartspier (Yang et al., 1998; Winegrad, 1999; Marston et al., 2009). Haplo-insufficiëntie betekent dat een haploïde dosis, dus afkomstig van één normaal functioneel allel, van een product niet voldoende is om een normaal fenotype te geven; met andere woorden de mutatie is dominant. In de meeste gevallen van HCM maakt het mutante allel wel een eiwit. Dit abnormale eiwit kan gedegradeerd worden door het ubiquitineproteasoom systeem. Door de gedaalde efficiëntie van dit systeem bij het verouderen, worden minder abnormale producten afgebroken. Door het opstapelen van deze eiwitten ontstaan klinische tekenen dus meestal op latere leeftijd (Tao et al., 2013).

In het mutante allel kan ook een vroegtijdig stopcodon aanwezig zijn, waardoor een zogenaamd 'poison peptide' gevormd wordt. Ook de vorming van poison peptides zou aan de basis kunnen liggen van het ontstaan van pathologische veranderingen. Poison peptides kunnen binden aan myofilamenten, waardoor ze de mechanische functie van de sarcomeren en de elektrofysiologische werking van de cardiocyten aantasten. Enerzijds kunnen zij de gecoördineerde contractie van myofilamenten beïnvloeden, anderzijds worden de actine-geactiveerde ATPase-activiteit en krachtontwikkeling aangetast door het verhogen van de $\mathrm{Ca}^{2+}$-sensitiviteit en -affiniteit. 
Welk van de mechanismen verantwoordelijk is voor het ontwikkelen van HCM, zou afhankelijk zijn van het type mutatie. Yang et al. (1998) voerden studies uit met transgene muizen met mutaties in Mybpc3. Deze studies hebben aangetoond dat sarcomeren abnormaal chaotisch geordend zijn en dat papillairspieren een verminderde maximale kracht bezitten. Er is een toegenomen gevoeligheid voor calcium. Dit laatste kan leiden tot een verhoogde diastolische druk en leidt zo tot diastolische dysfunctie (Hofmann et al., 1991; Frazier et al., 2011). De invloed van mutaties op de contractiliteit van het hart is nog niet volledig bekend. Afhankelijk van de locatie van de genetische mutatie, zou er hypercontractiliteit of hypocontractiliteit van de sarcomeren kunnen optreden. Beide vormen kunnen leiden tot hetzelfde fenotype, waarschijnlijk omdat beide leiden tot een verhoogde energetische kost (Flashman et al., 2004).

Familiale HCM wordt, afhankelijk van de bron, in ongeveer $20-42 \%$ van de gevallen veroorzaakt door mutaties in het MYBPC3-gen (Richard et al., 2003; $\mathrm{Xu}$ et al., 2010). Cardiomyopathie als gevolg van mutaties in MYBPC3, is over het algemeen goedaardig (Winegrad, 1999; Wang et al., 2008; Xu et al., 2010). Vergeleken met andere mutaties ter hoogte van sarcomeereiwitten, vertonen patiënten op latere leeftijd symptomen en zullen ze zelden of nooit plots sterven (Wang et al., 2008). Er werden reeds meer dan 150 polymorfismen in dit gen ontdekt (Richard et al., 2006; Xu et al., 2010).

\section{Andere genetische oorzaken}

Naast veranderingen in de sarcomeren kunnen ook metabole stoornissen oorzaak zijn van hypertrofische cardiomyopathie. Aandoeningen van de glycogeenopslag, zoals de ziekte van Pompe, Fabry of Danon, en aandoeningen van de lysosomale opslag van $\alpha$-galactosidase A, zoals de ziekte van AndersonFabry, kunnen hiertoe aanleiding geven. Ook stoornissen in het vetzuurmetabolisme en deficiënties van carnitine of fosforylase B-kinase kunnen de oorzaak zijn van hypertrofische cardiomyopathie (Elliott et al., 2008).

Tot slot kunnen genetische mutaties in mitochondriaal DNA betrokken zijn. Deze worden overgedragen via de moeder (Odawara en Yamashsita, 1999).

\section{MUTATIES IN HET GENOOM EN HET VER- BAND MET CARDIOMYOPATHIE BIJ DE KAT}

Bij de maine-coonkat komen twee mutaties in MYBPC3 zeer vaak voor, namelijk mutatie A31P (Meurs et al., 2005) en A74T (Nyberg et al., 2007). Net zoals bij de mens worden deze mutaties autosomaal overgedragen en is er sprake van onvolledige penetrantie en variabele expressie (Mary et al., 2010).

Bij mutatie A31P is alanine in het $31^{\mathrm{e}}$ codon om- gezet naar proline. Het is mogelijk dat deze mutatie plaatsvindt in een regio die van belang is in de binding met myosine en/of actine (Meurs et al., 2005). Bij onderzoek naar myocardiale eiwitten werd bij dragers van deze genetische mutatie een reductie vastgesteld van MYBPC3 en van myomesine (een M-band-eiwit). Een duidelijke malformatie van de sarcomeren is zichtbaar (Meurs et al., 2005). Er zijn reeds verschillende studies uitgevoerd bij maine-coonkatten, waarbij de prevalentie van de mutatie A31P werd onderzocht. Volgens Mary et al. (2010) komt de mutatie voor bij 41,5\% van de katten van het maine-coonras. Volgens Fries et al. (2008) is dit 34\% en volgens Wess et al. (2010) 22\%. Dit verschil is waarschijnlijk te wijten aan de geografische origine van de katten. De mutatie werd niet gevonden bij katten van een ander ras, met uitzondering van één Britse korthaar (Mary et al., 2010), één ragdoll en één Siberische kat (Fries et al., 2008). Deze dieren bezaten deze mutatie mogelijk omdat een van de voorouders een maine-coonkat zou geweest zijn of, minder waarschijnlijk, door een de novo-mutatie (Fries et al., 2008; Mary et al., 2010).

Bij mutatie A74T wordt de eiwitstructuur gewijzigd doordat in het $74^{\mathrm{e}}$ codon arginine plaats maakt voor tryptofaan. De mutatie A74T komt voor bij 34\% van de katten van het maine-coonras en bij $62 \%$ van katten van variabele andere rassen, zoals de pers, de Europese korthaar en de Noorse boskat (Wess et al., 2010). Later onderzoek heeft echter aangetoond dat de laatstgenoemde mutatie toch niet gecorreleerd is met de ontwikkeling van hypertrofische cardiomyopathie (Longeri et al., 2013) (Figuur 1).

Ook bij de ragdoll werd er een rasspecifieke mutatie geïdentificeerd, namelijk een arginine-naartryptofaanmutatie ter hoogte van codon 820 (R820W). Het precieze werkingsmechanisme van deze mutatie is niet bekend, maar het is waarschijnlijk dat de eiwit-

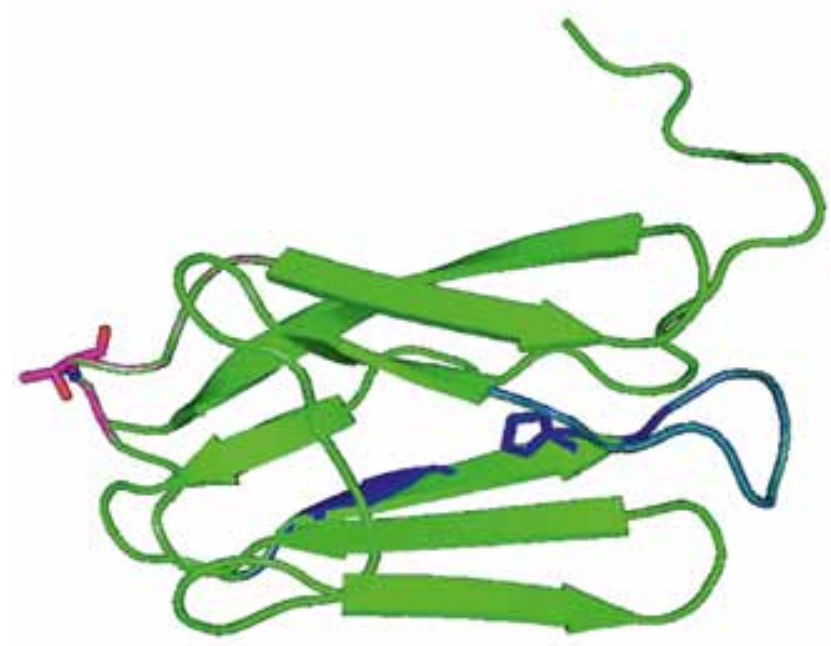

Figuur 1. Het eerste domein van eiwit MYBPC3. Hierop wordt het wilde type weergegeven (groen) en de genmutaties A31P (blauw) en A47T (roze). De pijlen geven de $\beta$-strengen weer, de strengachtige structuren staan voor residuen 31 en 47 van de genmutaties (Longeri et al., 2013). 
functie of -structuur aangetast wordt door een breuk in de $\alpha$-helix en de $\beta$-sheet. Er is ook een verhoogde hydrofobiciteit. De verdikking van de linkerventrikelwand kan op een gemiddelde leeftijd van 15 maanden echocardiografisch vastgesteld worden, maar hypertrofie kan in principe op elke leeftijd van start gaan (Meurs et al., 2007). Het fenotype van deze mutatie is ernstiger dan de mutatie bij de maine-coonkat. Tot op heden werden geen andere mutaties geïdentificeerd bij de ragdoll (Meurs et al., 2007; Mary et al., 2010).

Bij de overige kattenrassen zijn tot op heden geen rasspecifieke mutaties gevonden. Wel is er reeds een familiale link gerapporteerd bij de Britse korthaar. Binnen één familie kunnen vaak dezelfde ziektesymptomen worden vastgesteld (Granström et al., 2011).

Zeker 60\% van de gevallen van HCM bij katten is het gevolg van een genmutatie (Meurs et al., 2005). Het merendeel van de aangetaste katten is mannelijk. Deze geslachtspredispositie kan te wijten zijn aan factoren, zoals modificerende genen of hormonen (Mary et al., 2010). Niet alle katten met hypertrofische cardiomyopathie zijn positief voor de bekende mutaties. Er moeten dus nog andere mutaties of modificerende genen aanwezig zijn. Deze werden tot op heden nog niet geïdentificeerd bij de kat (Wess et al., 2010).

Net zoals bij de mens is HCM bij de kat genetisch heterogeen en varieert het verloop van de ontwikkeling van hartspierschade, afhankelijk van het genotype van het dier. Identieke mutaties kunnen gelijkende pathologische veranderingen geven bij verschillende dieren, terwijl deze veranderingen zeer sterk kunnen verschillen van andere mutaties. Het fenotype van de aangetaste katten in een studie uitgevoerd door Meurs et al. (2005) varieerde van matige tot ernstige hypertrofische cardiomyopathie. Er zijn nog niet voldoende onderzoeken gedaan om de link te leggen tussen het genotype en de klinische afloop, maar het is wel duidelijk dat homozygoot aangetaste dieren lijden aan een ernstiger fenotype dan heterozygote dieren (Eijssen et al., 2008).

\section{GENETISCHE TESTEN}

\section{Genetische testen bij de mens}

DNA-onderzoek heeft ertoe bijgedragen dat heden veel meer bekend is over de genetische etiologie van hypertrofische cardiomyopathie. Genetische testen kunnen specifieke genmutaties opsporen die verantwoordelijk zijn voor hartspierziekte bij patiënten. Hierdoor kunnen eventueel genotypisch positieve familieleden herkend worden, maar het draagt ook bij tot verdere studies over de pathogenese en de ontwikkeling van nieuwe strategieën betreffende ziektepreventie en therapie (Ho, 2012).

Tegenwoordig zijn er veel verschillende moleculaire diagnostische technieken ter beschikking om genmutaties als oorzaak van humane HCM op te spo- ren (Roma-Rodrigues en Fernandes, 2014). Bovendien wordt een aantal genen onderzocht die geassocieerd worden met metabole of mitochondriale ziekten en die ook kunnen leiden tot verdikking van de linkerventrikelwand (Ho, 2012). Er moet echter rekening mee gehouden worden dat nog niet alle pathogene mutaties geïdentificeerd zijn, waardoor nog regelmatig valsnegatieve uitslagen bekomen worden. Volgens Marian en Roberts (2003) kan bij 30\% van de humane patienten via genetische testen geen oorzakelijke mutatie gevonden worden. Wanneer men op een mutatie stuit, moet onderzocht worden of deze DNA-variant werkelijk de oorzaak van hartspierziekte kan zijn.

\section{Genetische testen bij de kat}

Voor de maine-coon en ragdoll zijn commerciële testen beschikbaar om respectievelijk de mutaties A31P en R820W in het MYBPC3-gen op te sporen. Aangezien de mutaties rasspecifiek zijn, kunnen de testen enkel gebruikt worden bij deze rassen. Een negatief resultaat voor bovenvermelde mutaties wil echter niet zeggen dat de kat gedurende zijn leven geen HCM kan ontwikkelen, omdat er waarschijnlijk nog meer mutaties betrokken zijn bij het ontstaan van hypertrofische cardiomyopathie. Ook niet alle positief geteste katten vertonen later symptomen. Fokadviezen kunnen dus het beste niet alleen gegeven worden op basis van genetische testen op mutatie A31P en R820W (Wess et al., 2010). Indien ook de familiale context en/of de stamboomgegevens in het onderzoek betrokken worden, zijn de resultaten van een genetisch onderzoek correcter te interpreteren.

\section{CONCLUSIE}

Over de jaren heen zijn er bij de mens reeds zeer veel mutaties geïdentificeerd die (mede)verantwoordelijk zijn voor de ontwikkeling van hypertrofische cardiomyopathie. Nochtans zijn er waarschijnlijk nog veel meer mutaties die tot op heden onbekend zijn. Kennis en detectie van dergelijke mutaties zijn belangrijk voor de preventie, diagnose, therapie en prognose van de aandoening. Zowel bij mens als dier dienen nog veel onderzoeken uitgevoerd te worden naar genmutaties in de sarcomeerproteïnen.

Bij de mens werden al honderden polymorfismen aangetroffen in genen die coderen voor dertien sarcomeereiwitten. Bij de kat werden slechts drie mutaties gedetecteerd (waarvan één hoogstwaarschijnlijk niet gecorreleerd is met hypertrofische cardiomyopathie), alle in het gen dat codeert voor cardiogene myosinebindingsproteïne $\mathrm{C}$.

Terwijl er bij de mens al veel bekend is over het werkingsmechanisme van de verschillende mutaties, is dit bij de kat nog niet het geval. De mutaties bij de mens zijn bijna alle verantwoordelijk voor een ver- 
hoogde $\mathrm{Ca}^{2+}$-sensitiviteit en er kan verondersteld worden dat dit een gemeenschappelijke factor is in de ontwikkeling van de hartaandoening. Aangezien de klinische en histopathologische kenmerken van HCM veel gelijkenissen vertonen tussen mens en kat, is het werkingsmechanisme vermoedelijk hetzelfde bij de twee species. Tot op heden is er echter slechts weinig onderzoek gedaan naar de structuur en eigenschappen van sarcomeereiwitten bij huisdieren. Zolang er via wetenschappelijk onderzoek nog geen verbanden zijn gelegd, kan informatie verkregen bij humane patiënten niet geëxtrapoleerd worden naar feliene patiënten en vice versa.

Alhoewel er reeds veel onderzoek verricht is naar deze vaak voorkomende hartziekte, is er nog te weinig bekend over de detectie en preventie van de aandoening. Met een prevalentie van $15 \%$ in de kattenpopulatie is het van groot belang dat hier een duidelijk antwoord op gevonden wordt.

\section{LITERATUUR}

Brouwer W.P., van Dijk S.J., Stienen G.J.M., van Rossum A.C., van der Velden J., Germans T. (2010). The development of familial hypertrophic cardiomyopathy: from mutation to bedside. European Journal of Clinical Investigation 41, 568-578.

Eijssen L.M.T., van den Bosch B.J.C., Vignier N., Lindsey P.J., van den Burg C.M.M., Carrier L., Doevendans P.A., van der Vusse G.J., Smeets H.J.M. (2008). Altered myocardial gene expression reveals possible maladaptive processes in heterozygous and homozygous cardiac myosin binding protein $\mathrm{C}$ knockout mice. Genomics 91, 52-60.

Elliott P., Andersson B., Arbustini E., Belinska Z., Cecchi F., Charron P., Dubourg O., Kühl U., Maisch B., McKenna W.J., Monserrat L., Pankuweit S., Rapezzi C., Seferovic P., Tavazzi L., Keren A. (2008). Classification of the cardiomyopathies: a position statement from the European society of cardiology working group on myocardial and pericardial diseases. European Heart Journal 29, 270-276.

Flashman E., Redwood C., Moolman-Smook J., Watkins H. (2004). Cardiac myosin binding protein C: It's role in physiology and disease. Circulation 94, 1279-1289.

Frazier A.H., Ramirez-Correa G.A., Murphy A.M. (2011). Molecular mechanisms of sarcomere dysfunction in dilated and hypertrophic cardiomyopathy. Progress in Pediatric Cardiology 31, 29-33.

Fries R., Heaney A.M., Meurs K.M. (2008). Prevalence of the myosin-binding protein $\mathrm{C}$ mutation in Maine Coon Cats. Journal of Veterinary Internal Medicine 22, 893896.

Granström S., Nyberg Godiksen M.T., Christiansen M., Pipper C.B., Willesen J.T., Koch J. (2011). Prevalence of hypetrophic cardiomyopathy in a cohort of British Shorthair cats in Denmark. Journal of Veterinary Internal Medicine 25, 866-871.

Haggstrom J. (2003). Hypertrophic cardiomyopathy in cats -- it used to be simple! Journal of Feline Medicine and Surgery 5, 139-141.

Ho C.Y. (2012). Genetic considerations in hypertrophic cardiomyopathy. Progress in Cardiovascular Diseases 54, 456-460.

Hofmann P.A., Hartzell H.C., Moss R.L. (1991). Alteration in $\mathrm{Ca} 2+$ sensitive tension due to partial extraction of $\mathrm{C}$-protein from rat skinned cardiac myocytes and rabbit skeletal muscle fibers. The Journal of General Physio$\log$ 97, 1141-1163.

Kienle R.D. (2008). Feline cardiomyopathy. In: Tilley L.P., Smith F.W.K., Oyama M.A., Sleeper M.M. (Editors). Manual of Canine and Feline Cardiology. Saunders Elsevier, Missouri, p. 151-175.

Kittleson M.D., Meurs K.M., Munro M.J., Kittleson J.A., Liu S., Pion P.D., Towbin J.A. (1999). Familial hypertrophic cardiomyopathy in Maine Coon Cats: An animal model of human disease. Journal of the American Heart Association 99, 3172-3180.

Klues H.G., Roberts W.C., Maron B.J. (1991). Anomalous insertion of papillary muscle directly into anterior mitral leaflet in hypertrophic cardiomyopathy. Significance in producing left ventricular outflow obstruction. Circulation 84, 1188-1197.

Kuster D.W.D., Bawazeer A.C., Zaremba R., Goebel M., Boontje N.M., van der Velden J. (2012). Cardiac myosin binding protein $\mathrm{C}$ phosphorylation in cardiac disease. Journal of Muscle Research and Cell Motility 33, 43-52.

Longeri M., Ferrari P., Knafelz P., Mezzelani A., Marabotti A., Milanesi L., Pertica G., Polli M., Brambilla P.G., Kittleson M., Lyons L.A., Porciello F. (2013). Myosinbinding protein $\mathrm{C}$ DNA variants in domestic cats (A31P, A74T, R820W) and their association with hypertrophic cardiomyopathy. Journal of Veterinary Internal Medicine 27, 275-285.

Marian A.J., Roberts R. (2003). To screen or not is not the question - it is when and how to screen. Circulation 107, 2171-2174.

Maron B.J., Gardin J.M., Flack J.M., Gidding S.S., Kurosaki T.T., Bild D.E. (1995). Cardiomyopathy in a general population of young adults. Echocardiographic analysis of 4111 subjects in the CARDIA study. Circulation 92, 785-789.

Maron B.J., Maron M.S. (2012). Hypertrophic cardiomyopathy. Lancet 318, 242-55.

Maron B.J., Maron. M.S., Semsarian C. (2012). Genetics of hypertrophic cardiomyopathy after 20 years. Journal of the American College of Cardiology 60, 705-715.

Marston S., Copeland O., Jacques A., Livesey K., Tsang V., McKenna W.J., Jalilzadeh S., Carballo S., Redwood C., Watkins H. (2009). Evidence from human myectomy samples that $M Y B P C 3$ mutations cause hypertrophic cardiomyopathy through haploinsufficiency. Circulation 105, 219-222.

Mary J., Chetboul V., Carlos Sampedrano C., Abitbol M., Gouni V., Trehiou-Sechi E., Tissier R., Queney G., Pouchelon J., Thomas A. (2010). Prevalence of the MYB$P C 3-A 31 P$ mutation in a large European feline population and association with hypertrophic cardiomyopathy in the Maine Coon breed. Journal of Veterinary Cardiology $12,155-161$.

Meurs K.M., Sanchez X., David R.M., Bowles N.E., Towbin J.A., Reiser P.J., Kittleson J.A., Munro M.J., Dryburgh K., MacDonald K.A., Kittleson M.D. (2005). A cardiac myosin binding protein $\mathrm{C}$ mutation in the Maine Coon cat with familial hypertrophic cardiomyopathy. Human Molecular Genetics 14, 3587-3593.

Meurs K.M., Norgard M.M., Ederer M.M., Hendrix K.P., 
Kittleson M.D. (2007). A substitution mutation in the myosin binding protein $\mathrm{C}$ gene in ragdoll hypertrophic cardiomyopathy. Genomics 90, 261-264.

Meurs K.M., Norgard M.M., Kuan M., Haggstrom J., Kittleson M. (2009). Analysis of 8 sarcomeric candidate genes for feline hypertrophic cardiomyopathy mutations in cats with hypertrophic cardiomyopathy. Journal of Veterinary Internal Medicine 23, 840-843.

Nyberg M.T., Koch J., Christiansen M. (2007) Intra-allelic genetic heterogeneity of hypertrophic cardiomyopathy in the Maine Coon Cat. In: Proceedings of the 12th Human Genome Meeting. Montreal, Canada, 2007.

Odawara M., Yamashita K. (1999). Mitochondrial DNA abnormalities in hypertrophic cardiomyopathy. Lancet $353,150$.

Paige C.F., Abbott J.A., Elvinger F., Pyle L. (2009). Prevalence of cardiomyopathy in apparently healthy cats. Journal of the American Veterinary Medical Association 11, 1398-1403.

Richard P., Charron P., Carrier L., Ledeuil C., Cheav T., Pichereau C., Benaiche A., Isnard R., Dubourg O., Burban M., Gueffet J.P., Millaire A., Desnos M., Schwartz K., Hainque B., Komaida M. (2003). Hypertrophic cardiomyopathy: distribution of disease genes, spectrum of mutations, and implications for a molecular diagnosis strategy. Circulation 17, 2227-2232.

Richard P., Villard E., Charron P., Isnard R. (2006). The genetic bases of cardiomyopathies. Journal of the American College of Cardiology 48, A79-89.

Roma-Rodrigues C., Fernandes A.R. (2014). Genetics of hypertrophic cardiomyopathy: advances and pitfalls in molecular diagnosis and therapy. The Application of Clinical Genetics 7, 195-208.

Tao T., Yaxin L., Xianliang Z., Lei S. (2013). Progress in the molecular genetics of hypertrophic cardiomyopathy: a mini-review. Gerontology 59, 199-205.

Van Driest S.L., Ommen S.R., Tajik A.J., Gersh B.J., Ackerman M.J. (2005). Yield of genetic testing in hypertrophic cardiomyopathy. In: Mayo Clinic Proceedings 6, 739-744.

Wang S., Zou Y., Fu C., Xu X., Wang J., Song L., Wang H., Chen J., Wang J., Huan T., Hui R. (2008). Worse prognosis with gene mutations of beta-myosin heavy chain than myosin-binding protein $\mathrm{C}$ in Chinese patients with hypertrophic cardiomyopathy. Clinical Cardiology 3, 114-118.

Wess G., SchinnerC., Weber K., KüchenhoffH., Hartmann K. (2010). Association of A31P and A74T polymorphisms in the myosin binding protein $\mathrm{C} 3$ gene and hypertrophic cardiomyopathy in Maine Coon and other breed cats. Journal of Veterinary Internal Medicine 24, 527532.

Xu Q., Dewey S., Nguyen S., Gomes A.V. (2010). Malignant and benign mutations in familial cardiomyopathies: insights into mutations linked to complex cardiovascular phenotypes. Journal of Molecular and Cellular Cardiology 48, 899-909.

Yang Q., Sanbe A., Osinska H., Hewett T.E., Klevitsky R., Robbins J. (1998). A mouse model of myosin binding protein $\mathrm{C}$ human familial hypertrophic cardiomyopathy. Journal of Clinical Investigation 102, 1292-1300.

\section{Fertiliteitshandelingen door de bedrijfsdierenarts binnen een CRV-totaaloplossing}

Het is velen bekend dat CRV totaaloplossingen aanbiedt voor rundveehouders om hun veestapel optimaal te laten presteren. Een belangrijk onderdeel hierbij is het verbeteren van de vruchtbaarheid. Het spreekt voor zich dat fertiliteitshandelingen als een belangrijk onderdeel hiervan kunnen beschouwd worden.

Binnen deze vruchtbaarheidsprotocollen heeft CRV nu ook een model ontwikkeld waarin de expertise van de bedrijfsdierenarts kan gevaloriseerd worden: binnen het kader van een totaaloplossing met een tochtdetectiesysteem en sperma-afname door veehouders die zelf insemineren is in dit model voorzien dat de bedrijfsdierenarts de fertiliteit organiseert en hij/zij vlot toegang heeft tot de kengetallen in de crv-database. De facturatie aan de veehouder gebeurt door CRV en de bedrijfsdierenarts kan (een deel van) de uitgevoerde handelingen doorrekenen aan CRV aan een vastgelegd tarief per koe.

Indien $\mathrm{u}$ meent dat $\mathrm{u}$ klanten heeft, die interesse hebben in deze totaaloplossing, dan kan u contact opnemen met dr. Peter Vercauteren (Peter.Vercauteren@crv4all.com of tel 078154444 ). 